Proceedings of the XXIII Conference on Applied Crystallography, Krynica Zdrój, Poland, September 20-24, 2015

\title{
Phase Identification of Nanometric Precipitates in AlSi9Cu Alloy after Remelting by Laser Beam
}

\begin{abstract}
M. PaWlyta*, K. Labisz And K. Matus
Institute of Engineering Materials and Biomaterials, Silesian University of Technology, Gliwice, Poland

The aim of presented paper is an investigation of the structure changes in AlSi9Cu alloy after remelting by a laser beam. Scanning transmission electron microscopy was applied for structure characterization and precipitates phase identification. In the raw material, precipitates were larger and during remelting such precipitates were dissolved and very fast crystallization came next. Observed precipitates are generally uniform in size, shape, and chemical composition. Generally, after remelting precipitates are not uniformly distributed in the whole sample but areas with dense, nanometric precipitates are common. Numerous volumes with elongated Ti precipitates, identified as $\operatorname{Ti}\left(\mathrm{Al}_{1-x} \mathrm{Si}_{x}\right)_{3}$, were found. Observed precipitate can strongly affect material properties (even in a case of law $\mathrm{Ti}$ concentration) because it may act as a crystal nucleus for other phases.
\end{abstract}

DOI: 10.12693/APhysPolA.130.827

PACS/topics: 68.55.Nq, 81.30.Mh, 68.37.Ma

\section{Introduction}

Aluminum has attracted much attention in industry because of low weight, high reflectivity, high electrical and thermal conductivity and high corrosion resistance. However, the limitations according to mechanical strength restrict its practical application. Mechanical strength can be improved by precipitation hardening [1]. Strengthening by age hardening depends on the type, size, and volume fraction of particles that precipitate from supersaturated solid solution during suitable ageing treatments [2]. Effect of trace elements on precipitation has to be investigated also in context of aluminium recycling $[3,4]$. About $75 \%$ of the so far produced aluminum is still in use all over the world. As a result, the uncontrolled and increasing concentration of various trace elements in recycled material is observed. It is necessary to fully understand the effect of trace impurities on the properties, in particular, the changes in the structure of the produced material. This fact will be even more important in the near future if unconventional technologies are commonly used. An example of such technology is a surface laser alloying. The aim of presented paper is an investigation of the structure changes in $\mathrm{AlSi} 9 \mathrm{Cu}$ alloy after remelting by a laser beam.

\section{Experimental}

The investigation has been carried out on $\mathrm{AlSi} 9 \mathrm{Cu}$ aluminum alloy $(\mathrm{Al}-88 \%, \mathrm{Si}-9 \%, \mathrm{Cu}-1 \%, \mathrm{Fe}-$ $0.7 \%, \mathrm{Mn}-0.4 \%, \mathrm{Mg}-0.3 \%)$. The first sample was obtained from cast alloy after the heat treatment in the electric resistance furnace, with a heating rate of $80^{\circ} \mathrm{C} / \mathrm{s}$ for the ageing process and $300^{\circ} \mathrm{C} / \mathrm{s}$ for the solution heat treatment process with two holds at $300^{\circ} \mathrm{C}$ and $450^{\circ} \mathrm{C}$ performer for $15 \mathrm{~min}$. The solution heat treatment temperature was $505^{\circ} \mathrm{C}$ for $10 \mathrm{~h}$, and then ageing

*corresponding author; e-mail: miroslawa.pawlyta@polsl.pl was performed at $175^{\circ} \mathrm{C}$ for $12 \mathrm{~h}$. Second sample was additionally remelted by a laser beam (the high power diode laser HPDL Rofin DL 020, laser power - $1.5 \mathrm{~kW}$, laser scan rate $-0.25 \mathrm{~m} / \mathrm{s}$, temperature - up to $\left.3000^{\circ} \mathrm{C}\right)$. The bulk samples (raw and remelted by the laser beam) were cut into plate forms and then mechanically ground to thin foils. The specimens for electron microscopy were thinned by ion milling. Electron microscopy observations were done on a probe Cs-corrected S/TEM Titan 80$300 \mathrm{FEI}$ microscope equipped with EDAX EDS detector. A $300 \mathrm{kV}$, electron beam with a convergence semi-angle of 17 and $27 \mathrm{mrad}$ was used. The images were recorded in scanning transmission electron microscopy (STEM) mode, using the high-angle annular dark field (HAADF) detector. The sample was previously oriented in the direction $[001]_{\mathrm{Al}}$. For EDS analysis, larger beam current and larger convergence semi-angle (34 mrad) was used to increase the signal.

\section{Results and discussion}

The structure of raw $\mathrm{AlSi} 9 \mathrm{Cu}$ aluminum alloy (not remelted by the laser beam) is shown in Fig. 1 . The material contains numerous precipitates of different morphology. Most of them are spherical in shape, and their size usually exceeds $50 \mathrm{~nm}$. Maps of the $\mathrm{Al}, \mathrm{Cu}$, and $\mathrm{Si}$ distribution show that the precipitates are also very diverse in chemical composition (Fig. 2).

The most significant difference for the sample after remelting is visible on selected area diffraction pattern. It may be noted that for some parts of thin foil oriented in the $[100]_{\mathrm{Al}}$ direction diffraction pattern is similar to that shown in Fig. 3a. Diffraction pattern contains reflections originating from $\mathrm{Al}$ structure as well as some additional reflections, uniformly distributed in specific locations between the reflections of aluminum. DF image obtained on the basis of one of these reflections reveals the presence of nanometric coherent precipitates (Fig. 3b). For more efficient visualization of metastable precipitates imaging in STEM mode was applied. As the HAADF detector 


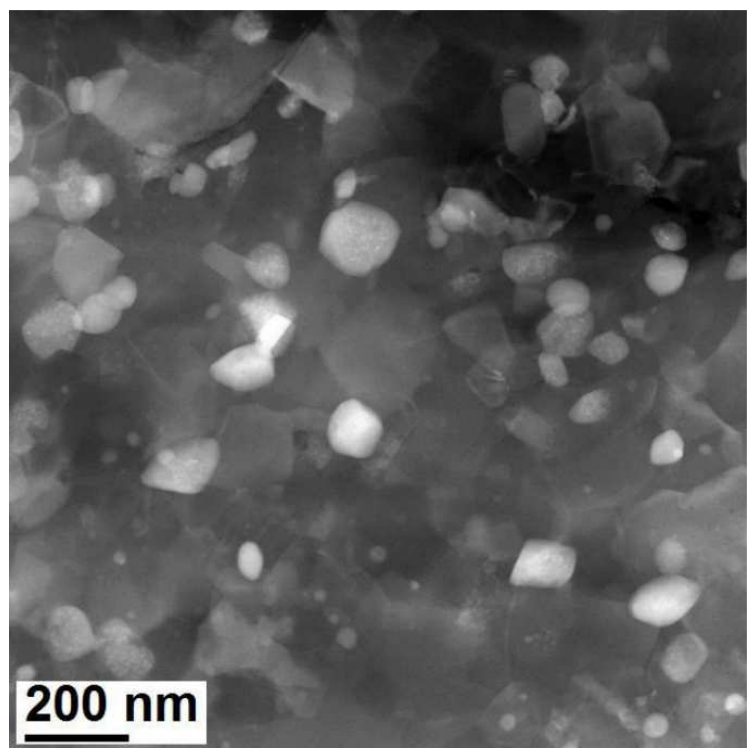

Fig. 1. Structure of raw (not remelted by laser beam) AlSi9Cu alloy. STEM-HAADF image.
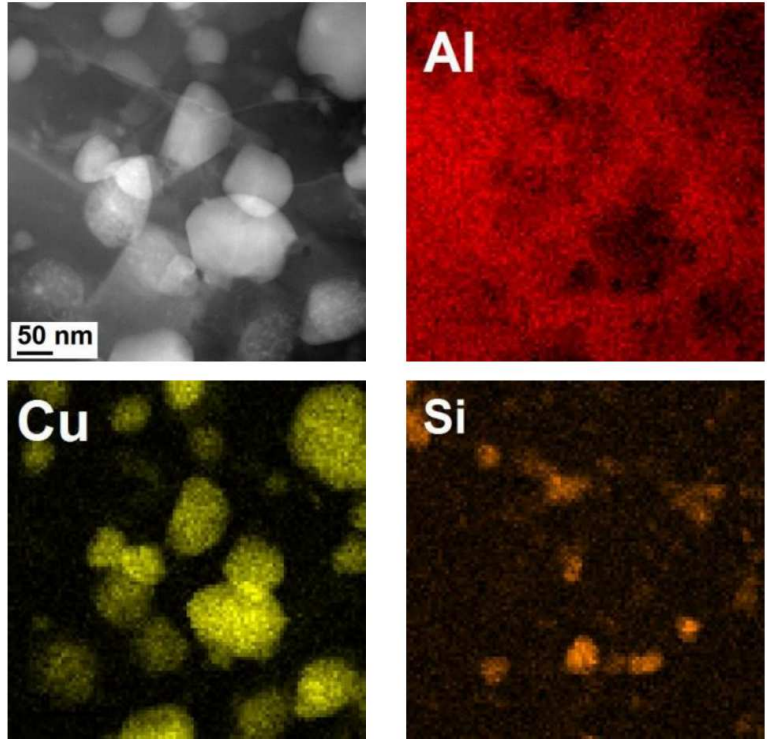

Fig. 2. STEM-BF image of magnified part from Fig. 1 and EDS X-ray mappings of $\mathrm{Al}, \mathrm{Cu}$, and $\mathrm{Si}$ distribution.

uses a contrast $Z$, precipitates with different than matrix chemical composition are seen as brighter or darker (than the matrix) areas. In Fig. 4 it can be seen that nanometric precipitates are densely and uniformly distributed. Their arrangement is random, and the vast majority has an elongated shape (length is approximately $100-500 \mathrm{~nm}$, width is approximately $20-30 \mathrm{~nm}$ ). A characteristic feature is that almost each of them is decorated by smaller one of different contrast (chemical composition).

Generally, after remelting precipitates are not uniformly distributed in the whole sample but areas with very small (nanometric) and dense precipitates are common. In the raw material, precipitates were larger and during remelting such precipitates were dissolved and very fast crystallization came next. Observed precipitates are generally uniform in size, shape, and chemical composition (although smaller precipitates are often located on their surface).
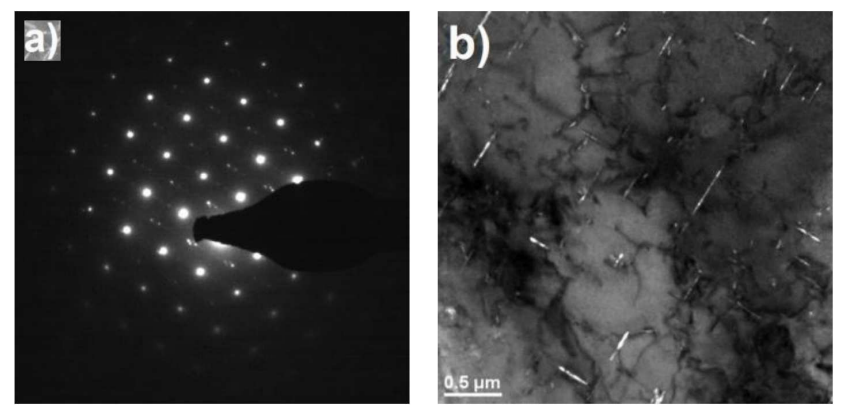

Fig. 3. Structure of remelted by laser beam AlSi9Cu alloy. SAED diffraction obtained from the area with coherent precipitates (a), and corresponding DF image (b).
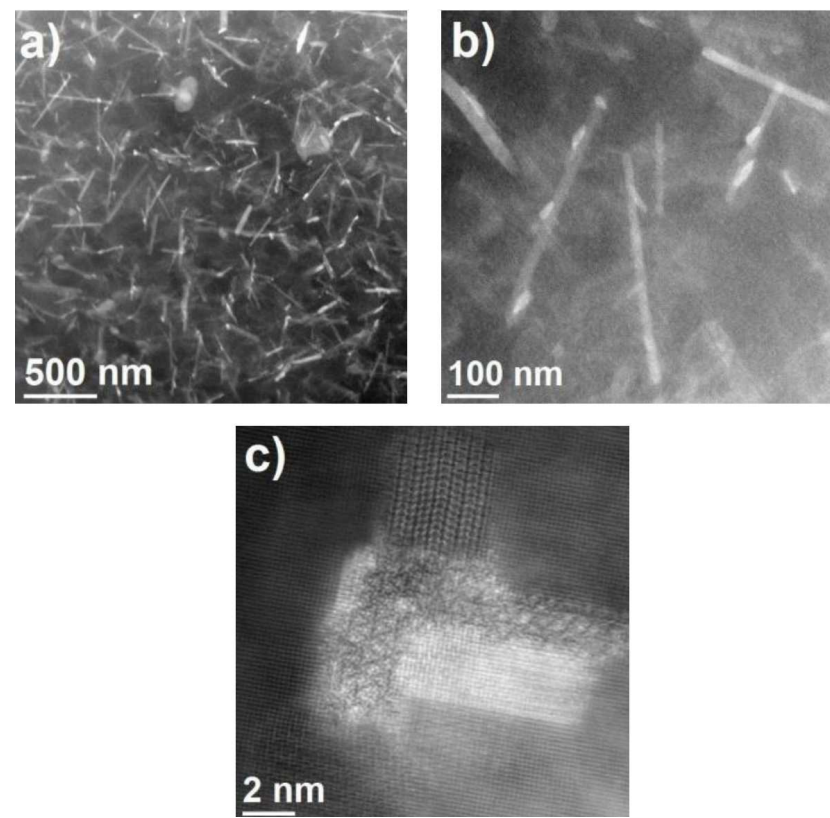

Fig. 4. STEM-HAADF images of AlSi9Cu alloy structure after remelting by a laser beam. Several nanometric precipitates with an elongated shape (a), a few precipitates decorated by other smaller precipitates of different contrast (b), strongly magnified tip of precipitate (c).

A typical precipitate with a complex structure is shown in Fig. 5. The EDS maps (the distribution of $\mathrm{Al}, \mathrm{Cu}, \mathrm{Mg}$, $\mathrm{Si}$, and $\mathrm{Ti}$ ) revealed that the skeleton of the observed structure consists of two sticks containing mainly Ti. On this skeleton, other particles were then nucleated. It indicates that $\mathrm{Ti}$ precipitates act as crystal nuclei for other phases.

In the next step, the phase containing $\mathrm{Ti}$ was identified. For this purpose for other selected precipitate (Fig. 6) chemical composition was determined (Fig. 6b) and high resolution STEM image was obtained (Fig. 6c). 

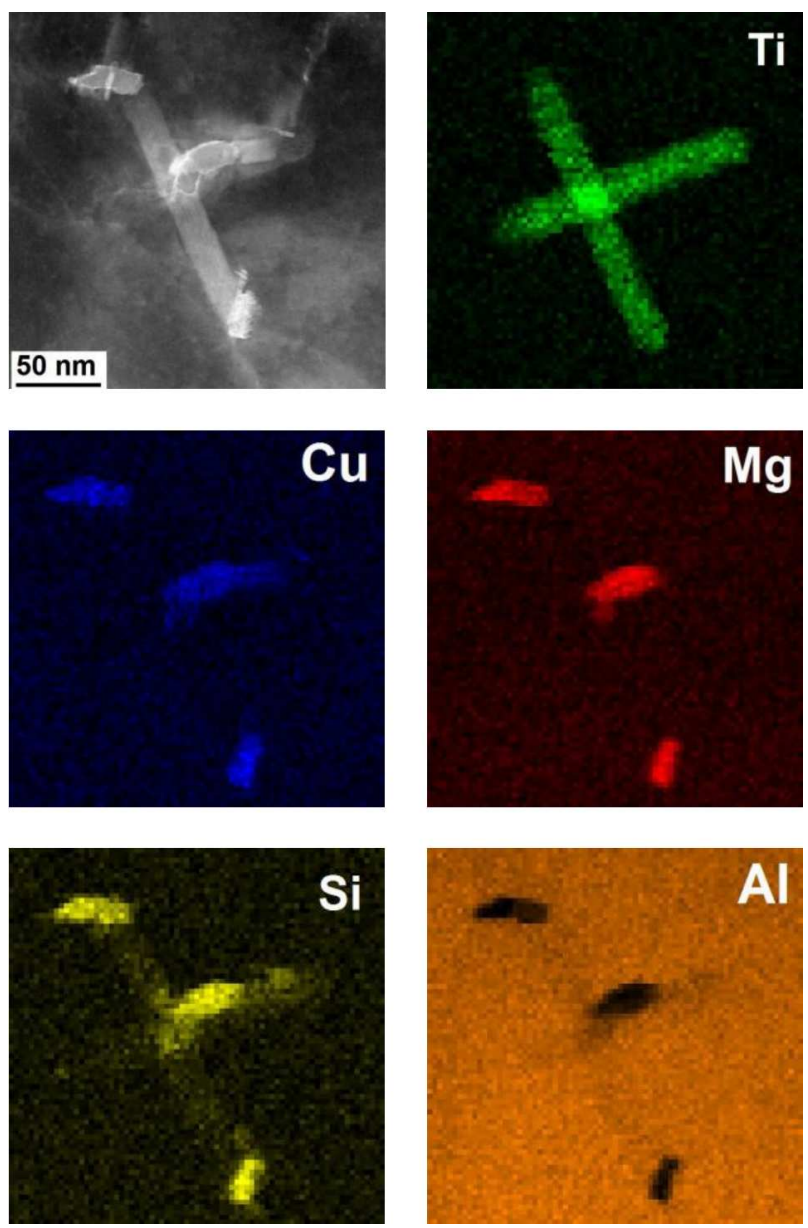

Fig. 5. STEM-HAADF image of the single precipitate with complex structure. EDS X-ray mappings of $\mathrm{Al}$, $\mathrm{Cu}, \mathrm{Mg}, \mathrm{Si}$, and $\mathrm{Ti}$ distribution.
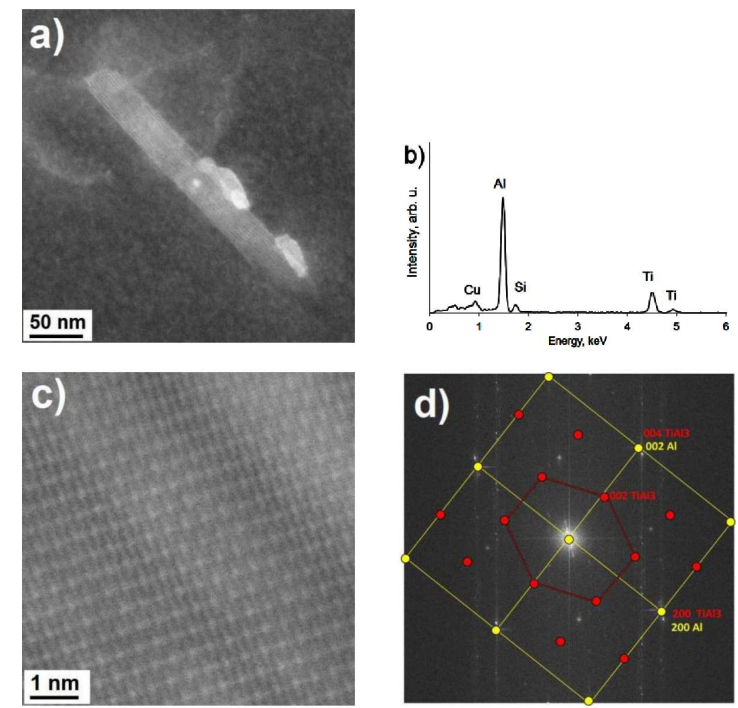

Fig. 6. STEM-HAADF image of the whole precipitate (a), the result of EDS analysis (b), high resolution STEM image of the central part of the precipitate (c), and its FFT (d).
Precipitate consists of $\mathrm{Al}, \mathrm{Ti}, \mathrm{Si}$, and $\mathrm{Cu}$. The presence of $\mathrm{Cu}$ is ambiguous. In that case, EDS results should be treated very carefully because it may be an effect of characteristic X-rays generated in the copper elements of a microscope. High resolution image reveals the crystal structure of analyzed precipitate. On the basis of FFT calculated for that image (Fig. 6d) phase can be initially identified as $\mathrm{TiAl}_{3}$ (tetragonal; space group: $I 4 / \mathrm{mmm}$; $a=0.3844 \mathrm{~nm}, c=0.8596 \mathrm{~nm}$; PDF No. 139). However, taking into account the results of EDS it appears that more reasonable would be to describe it as $\mathrm{Ti}\left(\mathrm{Al}_{1-x} \mathrm{Si}_{x}\right)_{3}$. The formation of a ternary phase $\mathrm{Ti}\left(\mathrm{Al}_{1-x} \mathrm{Si}_{x}\right)_{3}$ occurs gradual, i.e. Ti- and Al-rich binary phase forms first, and then the diffusion of Si leads to the formation of the ternary phase [5].

\section{Conclusions}

STEM was applied to investigate structure $\mathrm{AlSi} 9 \mathrm{Cu}$ alloy samples before and after remelting by a laser beam. Special attention was put on precipitates which contain Ti. In remelted material we have found that numerous volumes were elongated, nanometric Ti precipitates, identified as $\operatorname{Ti}\left(\mathrm{Al}_{1-x} \mathrm{Si}_{x}\right)_{3}$, were densely and uniformly distributed. Observed precipitates can strongly influence on material properties (even in a case of law Ti concentration) because they act as a crystal nucleus for other phases.

\section{References}

[1] E. Sjölander, S. Seifeddine, J. Mater. Process. Technol. 210, 1249 (2010).

[2] A. Wiengmoon, J.T. Pearce, T. Chairuangsri, S. Isoda, H. Saito, H. Kurata, Micron 45, 32 (2013).

[3] M.E. Schlesinger, Aluminum Recycling, CRC Press, Boca Raton 2013.

[4] K.G. Watkins, M.A. McMahon, W.M. Steen, Mater. Sci. Eng. A 231, 55 (1997).

[5] T. Gao, G. Liu, X. Liu, Mater. Character. 95, 285 (2014). 